\title{
Learning to take the tablet: How pre-service teachers use iPads to facilitate their learning
}

\author{
Mark Pegrum, Christine Howitt, and Michelle Striepe \\ The University of Western Australia, Australia
}

\begin{abstract}
Mobile handheld devices are spreading rapidly in education. iPads, especially, are increasingly being adopted by different educational sectors, but there is currently little empirical evidence on whether, or how, they facilitate student learning. This paper reports on how iPads contributed to pre-service teachers' learning, including their learning about teaching. Case studies of eight pre-service teachers were developed based on semistructured interviews and non-participant observations to determine how they used the iPad 2 in their learning. Focus group interviews of the larger cohort were also used to support findings. It was found that iPads supported pre-service teachers' learning in four ways: developing understanding of content, developing understanding of pedagogy, staying connected, and staying organised. More broadly, iPads helped them develop a new sense of learning spaces and learning networks. Three types of obstacles to using iPads as learning tools were also identified: device limitations, time limitations, and attitudinal limitations. Based on these findings, recommendations are made for developing pedagogical best practice for the use of iPads. These recommendations are relevant to pre-service teacher education in particular but also to higher education in general.
\end{abstract}

\section{Introduction}

Mobile handheld devices are spreading through all educational sectors, with Apple's iPad, the best-known representative of the new category of tablets, emerging as the field leader. Given the speed of these developments, there has been little empirical research published to date on whether, and how, iPads facilitate student learning. The current study explores how the iPad 2 contributed to the learning of a cohort of pre-service teachers, including their learning about teaching, based on eight case studies conducted over the course of a semester. The views of pre-service teachers are highly relevant to the future use of iPads and similar tools in educational settings since, on the one hand, they experience them as tools to support their learning and, on the other, they experience them as tools to improve their teaching and their own students' learning in the classroom.

\section{Learning with mobile devices}

Mobile learning, or m-learning, is learning mediated through digital mobile devices such as personal media players (including iPods), personal digital assistants (PDAs), smartphones (including iPhones), and tablets (including iPads). Mobile devices are distinguished from portable devices like laptops or netbooks by their greater mobility, which results from their smaller size and lower weight. Many also have the capacity to connect to the internet through $3 \mathrm{G}$ or $4 \mathrm{G}$ telephone networks in addition to Wi-Fi. In consequence, as noted by Puentedura (2012), while portable devices are typically used at Point A, closed down, and opened up again at Point B, mobile devices may be used at Point A, Point B and everywhere in-between. It has been predicted that internet-enabled mobile devices will outnumber PCs by 2013 (Johnson, Adams, \& Haywood, 2011, with reference to Gartner Research). As they spread, mobile handheld technologies are changing the way we find information, communicate, socialise and learn.

Digital technologies, especially those which relate to web 2.0, or the social web, can help support learnercentred pedagogical approaches (Pegrum, 2009). Mobile technologies, with their particular benefits such as portability, wide connectivity, flexibility, immediacy of communication, empowerment and engagement of learners, and active learning experiences, potentially represent a further move in this direction (JISC, 2005). Because mobile devices can foreground the social, communicative and collaborative aspects of learning experiences, it has been suggested that they can usefully complement contemporary pedagogical approaches like social constructivism (e.g., Cochrane \& Bateman, 2010; Cochrane, Narayan, \& Oldfield, 2011). Crucially, mobile devices enable learning that is situated and contextualised (e.g., Kukulska-Hulme, Sharples, Milrad, Arnedillo-Sánchez, \& Vavoula, 2009; Melhuish \& Falloon, 2010) and simultaneously personalised and individualised (e.g., McCaffrey, 2011; Pachler, 
Bachmair, \& Cook, 2010). Individual students are able to pursue their learning "seamlessly" across formal and informal contexts (Looi, Seow, Zhang, So, Chen, \& Wong, 2010) in their own manner and at their own pace. Thanks to their mobile devices, students also have perpetual access to the support of their personal learning networks, or PLNs (Ferriter, Ramsden, \& Sheninger, 2011; McElvaney \& Berge, 2009; Richardson \& Mancabelli, 2011).

Among mobile devices, tablets have been described as "a game-changer" because they offer similar tools to smartphones - without the interruption of phone calls - alongside a growing range of learning tools (Johnson et al., 2011, p. 15). Indeed, they are effectively a blend of smartphone and laptop, and can be customised for educational or other purposes thanks to the many thousands of available apps (Johnson, Adams, \& Cummins, 2012). Although companies such as Motorola, Samsung and Sony have entered the tablet market, Apple's iPad has emerged as the "category-defining blockbuster" (Johnson et al., 2011, p. 14) to the extent that "[d]espite policies that ban mobile devices in most schools, the iPad is changing the conversations on campuses" (p. 15). Increasingly, the K-12 sector is recognising the potential benefits of utilizing tablets, and especially iPads, as alternatives to desktop computers, laptops, and even textbooks (Oakley, Pegrum, Faulkner, \& Striepe, 2012). Thus, national governments (such as in Thailand) and state governments (such as in Australia) are supporting the rollout of tablets to large cohorts of school students (e.g., DEECD, n.d.; "ICT signs \$32m tablet PC contract", 2012; "iPads for young students", 2012), and school leaders are promoting these devices to parents and students.

The tertiary sector is also increasingly investing in mobile infrastructure, supporting programs to lend devices to students who would not otherwise have them, and building customised mobile apps (Johnson et al., 2012, p. 12). iPads have been the focus of numerous tertiary level ventures, both internationally, notably in the USA (e.g., GSMA, 2011a, 2011b), and in Australia (e.g., "iPads reinvent Adelaide science", 2011; Jennings, Anderson, Dorset, \& Mitchell, 2010).

\section{Research into learning with mobile devices}

As the practice of using mobile devices to support teaching and learning becomes more common across all educational sectors, research is underway around the world to determine the optimum educational uses for these devices. It is clear that mobile handheld devices are perceived by students, teachers and researchers as intrinsically engaging (e.g., Backer, 2010; Jones \& Issroff, 2007; Pachler et al., 2010), but evidence of improved learning outcomes is much more limited. A small number of studies have produced quantitative evidence of statistically significant improvements in student learning (e.g., Cristol \& Gimbert, 2011; Ernst \& Harrison, 2011; Hwang, Chen, \& Chen, 2011), though the wide range of devices, pedagogical approaches, content areas and levels considered makes it difficult to draw general conclusions, other than to say that m-learning appears to have the potential to improve learning outcomes on traditional assessments (Pegrum, Oakley, \& Faulkner, 2013). Most current research is qualitative in nature, with its main focus being teacher and student perspectives (e.g., Franklin \& Peng, 2008; Franklin, Sexton, Lu, \& Ma, 2007). In such a new field, this research is an important way of generating insights into teacher and student views not only on engagement and motivation, but on how mobile devices are used in practice to support teaching and learning, and what users perceive as their educational benefits and limitations.

Despite the great potential of mobile handheld devices to support social constructivist and related pedagogical approaches, as noted above, it is not at all clear that these devices are in fact being used in pedagogically optimal ways in all contexts. In an early study from 2006, Patten, Arnedillo-Sánchez, and Tangney noted that many uses of mobile handheld devices were not pedagogically oriented (such as administrative functions) or were pedagogically traditional, focusing on content transmission or behaviourist exercises, leading them to urge a move in a more constructivist direction. In the same year, Naismith, Lonsdale, Vavoula, and Sharples (2006) noted that mobile devices can support traditional pedagogical approaches, such as content transmission or behaviourist drills, just as much as they can support contemporary approaches. Two years later, Herrington, Herrington, Ferry, and Olney (2008) found that the use of mobile devices in higher education was frequently "pedagogically regressive" (p. 24). This makes it particularly important to explore teachers' and students' perspectives on the pedagogical affordances of mobile technologies like the iPad. 
Apple's iPad was released in 2010, the iPad 2 in 2011, and the iPad 3 and iPad 4 in 2012. To date, most published work about iPads in education has been descriptive, recounting the rollout of iPads in educational institutions (e.g., $\mathrm{Hu}, 2011$ ), with discussion of the benefits and drawbacks being largely speculative or anecdotal (e.g., Barack, 2010; Melhuish \& Falloon, 2010; Walters \& Baum, 2011). The benefits mentioned are typically aligned with perceptions of the positive potential of mobile handheld devices in general, as discussed above. Some educators, however, question the rapid adoption of these devices without due consideration of how they impact on student learning (Mather, 2012), while others have called for iPad developers to capitalise on the apparent potential of the device so that it is used to "actually improve learning" (Walters \& Baum, 2011, p. 7). It is important to note that the iPad 2, with the addition of cameras and the arrival of more creative apps, somewhat allayed the fears of those who saw the iPad 1 as largely a consumption tool (e.g., Kolowich, 2010), though many educators believe it is still better suited to consumption than production (Pegrum et al., 2013).

Only a small number of research studies have been published on the use of iPads in education. The 2010 Step Forward pilot trial of iPads across nine academic subjects at Trinity College, at the University of Melbourne, found that they were "effective, durable, reliable and achieve[d] their educational aims of going further, faster and with more fun" (Jennings et al., 2010, p. 4). This led to the rollout of iPads to the whole college the following year, though the report's authors cautioned that they were not a replacement for desktop or laptop computers but rather an "enhancement", a point echoed elsewhere in the literature (e.g., Kolowich, 2010; Oakley et al., 2012). Murray and Olcese (2011, p. 48) found that most iPad apps used in education were predicated on either content transmission or behaviourist drill and practice approaches, concluding that "the bulk of the applications written to run [on] iOS devices are woefully out of sync with modern theories of learning and skills student[s] will need to compete in the 21 st century". While they were referring to the iPad 1, this study serves as a caution that these devices are not immune from concerns about pedagogically regressive uses of mobile handheld technologies, as expressed in past studies, or indeed from broader concerns about limitations introduced by an app-based as opposed to a web-based approach to digital technologies (McKenzie, 2012; Quitney Anderson \& Rainie, 2012). On the other hand, Cochrane et al. (2011), who also examined the iPad 1, found support for "the pedagogical integration of the iPad within social constructivist learning environments" in a series of four case studies (p. 153). Clearly, then, there is some tension between the possible and actual uses of these devices, a situation further complicated by the release of the iPad 2, 3 and 4, about which empirical studies have yet to be published.

\section{Research questions}

This study investigates the current pedagogical uses of mobile devices in higher education, with a specific focus on the iPad 2. (It should be noted that while the iPad 3 and iPad 4 have improvements to their processors, displays and other features, they differ little from the iPad 2 in their fundamental capabilities.) Working with pre-service teachers, we were able to capture their perspectives on using iPads to support both their learning and their teaching. The study was governed by the following three research questions, with the second designed to elicit views on the collaborative aspects of working with iPads in seamless learning spaces, as suggested in the research literature on mobile handheld technologies.

1. How do pre-service teachers use iPads as learning tools?

2. How do pre-service teachers experience a new sense of learning spaces or learning networks when using iPads as learning tools?

3. What are pre-service teachers' perceptions of the limitations of using iPads as learning tools?

\section{Methodology}

\section{Design and participants}

A multiple case study design (Merriam, 2009) was adopted for this research. Case studies focus on a particular phenomenon and provide a holistic means of describing and interpreting it in context and from multiple perspectives (Merriam, 2009). Eight pre-service teachers self-selected to be the case studies. They were first year students in the Master of Teaching (Early Childhood) or Master of Teaching (Primary) programs in the Faculty of Education at The University of Western Australia. All 20 pre- 
service teachers in these programs had been loaned an iPad 2 towards the end of the first semester of the 2011 academic year. They had varying levels of prior experience with ICTs, but two weeks after receiving the iPads, all the pre-service teachers participated in the same two-hour workshop that demonstrated general uses of the iPad, how to access the internet, and how to select, download and use various apps. Table 1 provides an overview of the case study participants, showing age, program of enrolment and enrolment mode (full- or part-time), and highlighting the range of participants who volunteered for the research.

Table 1

Description of the eight case study participants

\begin{tabular}{llll}
\hline Name* & Age & Program & Study Mode \\
\hline Anna & 23 & Primary & Full-time \\
David & 32 & Primary & Full-time \\
Donna & 25 & Primary & Full-time \\
Jessica & 40 & Primary & Full-time \\
Lisa & 34 & Early Childhood & Part-time \\
Nancy & 30 & Early Childhood & Part-time \\
Rose & 25 & Early Childhood & Full-time \\
Ruth & 37 & Early Childhood & Full-time \\
\hline
\end{tabular}

Note. $*$ All participants have been given pseudonyms to protect their identities.

\section{Lecturers' use of iPads}

Of the seven lecturers within the two programs, the six who were based in the Faculty of Education received iPads at the same time as the students. As none had any prior experience with the devices, they received 10 weeks of individual tuition and support from an e-learning facilitator, who was on secondment to the Faculty under the Teaching Teachers for the Future project funded by the Australian Federal Government. This allowed the lecturers to explore how best to use the iPads to support their teaching and their students' learning within their respective subject areas. Ultimately, the varying ways they employed the devices reflected their capacity and willingness to incorporate them into their teaching as learning tools for the students. One lecturer did not use her iPad at all as she did not believe it would assist in teaching or learning. Two lecturers required their students to use their iPads primarily for the consumption of information, such as accessing course materials online or looking up particular websites during class. Three lecturers went beyond such passive uses, asking students to download and use appropriate apps in order to complete tasks or assignments. Consequently, students used the iPads to make audio and video recordings, develop mind maps, create lesson plans and deliver class presentations.

\section{Data Collection and Analysis}

Three methods of data collection were used: semi-structured interviews, a non-participant observation, and a focus group interview. A summary of the dates for data collection across Semester 2 (July to November, 2011) is shown in Table 2.

Table 2

Summary of dates for data collection

\begin{tabular}{lll}
\hline Date & Week(s) of Semester 2 & Event \\
\hline 16 May 2011 & prior to start of semester & iPads handed out \\
30 May 2011 & prior to start of semester & iPad workshop for pre-service teachers \\
4-26 August 2011 & $2-5$ & First set of interviews with participants \\
29 September & 8 & Observation during excursion \\
17 October - & $9-12$ & Second set of interviews with participants \\
10 November 2011 & after end of semester & Focus group interview \\
10 November 2011 & & \\
\hline
\end{tabular}


Two sets of semi-structured interviews were the main method of data collection and were employed to capture the case study participants' experiences using iPads as learning tools. In the first interview, the eight participants were asked about their personal and educational backgrounds and how they would characterise themselves as users of mobile handheld technologies. They were then asked how they thought the iPads were facilitating or would facilitate their learning; how they thought these devices were creating or would create a new sense of learning spaces or learning networks; and what they thought their limitations were. A non-participant observation, which involved observing the Early Childhood preservice teachers during a two-hour excursion to a local nature reserve, where they used the iPads to record evidence for an upcoming assignment, permitted a more in-depth understanding of how they were using the devices. The second interview with the eight case study participants occurred towards the end of the trial, after they had used the iPads in a number of settings, including on a three-week school practicum. It focused on how their use of the iPads had changed over the course of the semester and, using the initial interviews and subsequent non-participant observation as springboards, explored emerging insights on how these devices were, or were not, helping them to learn. Finally, after the end of the semester, fourteen pre-service teachers volunteered to participate in a focus group, whose purpose was to develop a better understanding of participants' perspectives on the iPads as learning tools, as well as how the experience of using these devices could be improved. The focus group consisted of six case study participants, three Early Childhood and three Primary pre-service teachers, along with six other Early Childhood and two other Primary pre-service teachers from the same cohort.

The interviews were fully transcribed and sent to participants for member checking. The non-participant observation was video-recorded, with segments played back to participants during the second interview to spur further insights into how the iPads were being used. A case study was developed for each participant, highlighting his or her uses and perceptions of the iPad as a learning tool. Constant comparative data analysis (Strauss \& Corbin, 1990) was used to identify themes that emerged from the interviews and observations as the cases were developed. A cross-case analysis identified common themes across the eight cases, as presented in this paper. The focus group comments were transcribed, and provided further details on the themes that emerged from the cross-case analysis.

As qualitative studies are concerned with establishing validity, meaningfulness, and trustworthy insights (Patton, 2002), triangulation at several levels was used to ensure the quality of the data and research findings. First, there was triangulation of the research methods - that is, use of multiple methods - which ensured that data generated were not simple artefacts of one specific method of collection (Merriam, 2009). Second, there was triangulation of data sources, that is, multiple persons were interviewed on multiple occasions. Such an approach helps to "map out or explain more fully, the richness and complexity of human behavior by studying it from more than one standpoint" (Cohen, Manion, \& Morrison, 2000, p. 112). Finally, interview transcripts were subject to member checking, and the video of the non-participant observation was replayed to participants to stimulate recall.

\section{Using iPads as learning tools}

Four common themes were identified from the cross-case analysis regarding how the pre-service teachers used iPads as learning tools: developing understanding of content, developing understanding of pedagogy, staying connected, and staying organised.

\section{Developing understanding of content}

The pre-service teachers reported using the iPads to assist their understanding of content in three fundamental ways: recording and recalling information, consolidating and extending knowledge, and reflecting on learning. This theme was largely connected with their own learning as students.

The first subtheme, Recording and Recalling Information, emerged from comments from all eight participants, who illustrated how their learning was improved by using iPads to download readings as well as to record, store and access notes in a variety of different real-world learning spaces. As Ruth put it:

As far as recording and documenting goes I use [the iPad] a lot and I can go back to refer to something a couple of times. Or when there are a lot of notes to take, I use it then because 
otherwise I find that I am too caught up in taking notes ... It is nice to be able to record and still engage yourself in the conversations. (Ruth, second interview, 4/11/11)

Other participants also reported that they utilised the iPads to record notes in various media, sometimes using their device's audio recording capabilities - like Ruth, above - and sometimes using its back-facing camera to take photos or make videos. This was often helpful in the completion of assignments. Rose, for example, used her iPad to make an audio recording: "We had to do an interview for a [Physical Education] assignment. So I took [the iPad] with me and recorded what [my interviewee] said and I used that to type the transcript" (Rose, second interview, 17/10/11). Lisa, meanwhile, took photos of the local nature reserve and was later able to consult these images on her iPad to "refresh" her memory: "It is definitely helpful in organising my assignments. Making sure that I am ticking all the boxes when I am looking through an assignment ... for recall and development" (Lisa, second interview, 7/11/11).

The second subtheme, Consolidating and Extending Knowledge, refers to instances where seven of the eight pre-service teachers used their iPads to locate and review information that reinforced or extended their learning. Anna provided a clear illustration of this:

If I am not able to understand something [like a mathematical concept] very well with the text ... looking at another site, it explained it differently and I could understand it better. There was this other site and it gave me a few more examples ... so I was able to consolidate that. (Anna, second interview, 17/10/11)

In this way, internet-enabled devices like iPads allow students to seek out alternative sources of information to the texts and lecture content provided in their courses, enabling them to find resources which are more appropriate to their individual levels of understanding at a given time. A particularly interesting example of the use of an iPad to supplement understanding during a lecture was provided by Donna:

[The iPad] helps to understand whatever is being spoken about ... helps to recall the content knowledge ... During [lecturer's name] class, she was talking about something on guided reading. So I just did a quick browse through on one of the websites. (Donna, second interview, 24/10/11)

It was notable that students benefited from guidance by lecturers on suitable strategies and appropriate apps for consolidating understanding in a variety of ways. Nancy, for example, explained how a lecturer had the students use a particular app to brainstorm key ideas from the previous class session. This helped her complete her assignments:

[The lecturer] would get us to bring up our mind map and try and remember what it was we had done the previous week. So we would talk amongst ourselves and eavesdrop on what the other groups were doing. Then we would create the mind map, which was great to cement in your mind what you learned ... it made it easier when you [were] going to write your assignment because it was right there. (Nancy, second interview, 3/11/11)

The third subtheme, Reflecting on Learning, is grounded in how three of the participants used the iPads to help them analyse and critically reflect on specific teaching and learning concepts, strategies or experiences. Once again, they took advantage of the iPads' recording and photographing capabilities and associated apps. In a typical example, Anna audio-recorded herself teaching in order to ascertain the effectiveness of her questioning skills:

I did [audio-] record one of my lessons. Only about 10 or 15 minutes of it ... I just played it and listened to it ... It was good just for me to reflect on that lesson and how I was questioning the children, getting their attention and seeing how I was responding to what they said. (Anna, first interview, 22/8/11)

Ruth took a slightly different approach, recording her students rather than herself, and employing a combination of pictures alongside audio recordings of children's language use as "a good tool for reflecting back" (Ruth, second interview, 24/10/11). It is encouraging that at least three participants engaged in a higher level of reflection of this kind. It appears that - as with the mind mapping app above 
- explicit lecturer modelling, as recommended by Cochrane et al. (2011), might encourage more students to do so.

\section{Developing understanding of pedagogy}

Seven participants made comments suggesting the iPads helped them to develop an understanding of various aspects of pedagogy in the classroom context, primarily relating to the areas of student engagement, group work, and selection of materials in the form of apps. This theme was connected more with the pre-service teachers' learning about teaching, rather than their own learning as students.

All seven discussed using iPads as a means of engaging children, whether it was starting a lesson with iPads, using them outside the classroom (and thereby tapping into the notion of seamless learning), or using them to help engage disengaged learners. As Jessica explained: "If you wanted to engage the nonpencil-and-paper student who sort of refuse[s] to engage in that way, I think that [the iPad] is really good" (Jessica, second interview, 24/10/11). Similarly, Lisa observed:

So ... children who are not able to use a pencil very well are able to use their fingers to make letters. That [is] empowerment for them; the fact that they can erase [a mistake] and not have the reminder that they failed or stuffed up. (Lisa, first interview, 15/8/11)

The limitation of not having access to a class set of iPads was noted by five of the case study participants and in the focus group interview. The pragmatics of working either one-on-one or in small groups was discussed, with some seeing the latter as advantageous while others saw it as restrictive, mirroring current discussions among qualified teachers about whether iPads are best used as individual or group work devices (Oakley et al., 2012; Pegrum et al., 2013). Ruth, like many teachers of young learners, saw group work as beneficial, commenting on the supportive nature of the learning that was taking place among three children using one iPad: "Initially we went around and they took turns [using the iPad] and then they started helping each other ... it was quite a little, dynamic group" (Ruth, first interview, 4/8/11). On the other hand, the following limitation was noted in the focus group:

In small groups [the children] are more involved. They all huddle together [around the iPad], it works. But if you want the hands-on stuff, that's when having more iPads in class would be handy. (Focus group interview, 10/11/11)

Four participants recognised the importance of being thoroughly familiar with their materials, in this case, the apps chosen for the classroom. They commented on the need to find the most appropriate app to use in a given context and to explore it carefully. They realised that even if an app initially appeared to offer what was necessary for a lesson, sometimes it turned out to be unsuitable or too complicated for their requirements. As Ruth commented: "I don't think I would try to do anything [with the app] that I hadn't thoroughly had a go with first" (first interview, 4/8/11).

Other subthemes related to pedagogy were mentioned by two or fewer case study participants, but also mentioned in the focus group interview. These included identifying the real purpose for using iPads; finding the right balance between using iPads and more traditional tools in the classroom; taking advantage of children's prior technological knowledge; modelling to children how to use various apps; and encouraging children to reflect on learning while using iPads. The fact that these larger pedagogical themes did not figure so prominently in most pre-service teachers' reflections suggests that program lecturers may need to do more to explicitly prompt such reflections. As seen in the case of the mind mapping app discussed above, lecturer guidance and modelling may have a dramatic impact on students' use of and thinking about devices like iPads. The pre-service teachers' comments on the pedagogical impact of iPads in their own teaching show that many of them had reflected on at least some key areas, such as engagement, group work, and materials, but explicit direction by lecturers might encourage more students to reflect on more themes related to best practice in the use of technology in the classroom.

\section{Staying connected}

Reflecting the strong themes of communication, connection and collaboration in the m-learning literature, six of the participants commented that the iPads were a means to learn about events, keep up to date with 
issues, and stay connected to other people. They were able to enhance their learning through sharing meaning with others, which, echoing the literature on personal learning networks (e.g., McElvaney \& Berge, 2009; Richardson \& Mancabelli, 2011), occurred simultaneously on a personal and social as well as a professional level.

The iPads were commonly used to read the news - which, given ongoing national and state changes in education, often contains items of direct professional relevance to pre-service teachers. As David commented, "I have used [the iPad] as a small portable web ... if I need to access ... the internet generally for the latest news, for email". He went on to elaborate on his attachment to keeping up to date with wider informational networks:

Actually it makes me more relatively attached because I will check the newspaper every day. I don't buy a newspaper normally. I don't have internet access at my house. So, checking it here for five minutes, I actually get more up to date and that is fantastic. (David, first interview, 8/8/11)

In addition, the pre-service teachers used the device to check the cohort's Facebook page, to message and email each other about issues relating to class or assignments, and/or to share photos and videos of their work. As Rose indicated, "When people have taken a photo and you see that it is a photo that you want, you can ask them to post it, and so a lot of our iPad photos are on our Facebook page" (Rose, first interview, 15/8/11). It was interesting to note that participants indicated that they received both educational and emotional support through their online network of peers, as illustrated by Ruth's comment:

So [Facebook] is used a lot; it is used regularly. There's the practical information as well as experimental stuff. These are the sorts of problems that I am having. Is anyone having these problems as well? Or, I need a resource for this. Has anyone found one? It is useful for emotional support as well as educational support. (Ruth, first interview, 4/8/11)

It is possible that the supportive peer network established by the pre-service teachers, notably on the Facebook platform, may carry forward into the future, seeding their professional learning networks and thus influencing their lifelong learning as teachers.

\section{Staying organised}

Five participants indicated that they used the iPads as storage devices for their readings, notes and emails. Several commented that the iPads helped them to keep everything in one single virtual space, accessible from whatever physical spaces they were in (Rose, first interview, 15/8/11; Ruth, first interview, 4/08/11; Nancy, second interview, 3/11/11). Ruth elaborated as follows:

[The iPad] is helping me with my organization ... I use the diary, the email is there, it is all in one spot. One of the applications I use when I take notes has different folders for the units. So I can go straight in and access notes from one space to another. That ability to organize and keep everything in one spot is handy. (Ruth, first interview, 4/08/11)

Rose found similar advantages in using her iPad as an organisational device:

I am very much a list person and so instead of me writing lists, as I usually do, and putting them everywhere and forgetting where they are, I can have [them] all in one place. That makes me more efficient, in that I know what I am supposed to be working on at what time. I can organize things a little bit clearer in my mind because I know where everything is. (Rose, first interview, 15/8/11)

This same participant also stored all her photos pertaining to the program on her iPad, which she found extremely useful when the time came to complete assignments:

A lot of our assignments ask for digital evidence, like photos. So if I know that I have everything that has to do with uni on my iPad, rather than having to go with my iPhone or 
my computer which has both my personal and uni photos - they are all sort of mixed up - I have all my solely uni photos on my iPad, so if I need to find something or refer to something then I know everything is there. (Rose, second interview, 17/10/11)

Other participants took advantage of the popular Dropbox app, which enabled them to access important artefacts and share them between their iPads and their computers. This app was described as "helpful" for their organisation by two different participants, with one stating: "I also used an application called Dropbox, which helps you to keep things between your computer and the iPad. Another student introduced me to that ... I suppose it is an organisational thing" (Nancy, second interview, 3/11/11).

\section{A new sense of learning spaces and learning networks}

All eight pre-service teachers accessed new kinds of learning spaces at the intersection of the real and the virtual. The mobility of the iPads meant that unlike bulkier laptops they could be, and were, taken almost anywhere and used in both fixed locations as well as on public transport. They thus fitted neatly with Puentedura's (2012) definition of mobile rather than portable devices, as cited earlier. Even without 3G connectivity - which, as noted below under Perceived limitations of iPads as learning tools, would have enhanced this aspect of their use - they provided a clear illustration of the move towards "seamless learning spaces" theorised by Looi et al. (2011). As these authors observe, with reference to earlier work in this area, the new phase of technology-enhanced learning is "marked by continuity of the learning experience across different scenarios or contexts, and emerg[es] from the availability of one device or more per student ('one-to-one') (Chan et al, 2006)" (p. 155). They go on to note that "[t]he learning space is no longer defined by the 'class' but by 'learning' unconstrained by scheduled class hours or specific locations" and add that while learning will sometimes be facilitated by teachers and peers in formal contexts, "at other times it could be student-initiated, impromptu and emergent" (pp. 156-157).

Evidence of such usage of mobile handheld devices emerged in our study. As Rose put it, "If I am on the train or I am in the waiting room somewhere I can just take [the iPad] out and I can read the readings" (Rose, first interview, 15/8/11). Significantly, the iPads made it possible for participants to take their personal learning networks with them, accessing them from any real-world context although, again, this was somewhat limited by the iPads' Wi-Fi-only configuration. Nevertheless, seven of the eight preservice teachers gave examples of accessing a learning network through their iPads, and this often occurred at different times and in different, Wi-Fi-enabled locations. The devices thus helped create a sense of ongoing connectedness to informational resources, as in the case of David, who accessed online news. Simultaneously, students described their ongoing access to the people in their learning networks, placing particular emphasis on the role of Facebook. Typical comments relating to Facebook included:

We are able to discuss how [the iPads] work and if one person does find something that is useful, then it is disseminated across large groups of people. (David, first interview, 8/8/11)

If there is something they have found out from a particular teacher ... especially as we don't see each other that much ... it has been a good idea and we have shared photos and resources. (Anna, first interview, 22/8/11)

The pre-service teachers also made use of their devices to create multimedia virtual records in real-world contexts which were later accessed in different contexts, as with Lisa's photos of the nature reserve described earlier. These multimedia records, often created in situations where there was little time for contemplation, could thus be revisited when there was more time to reflect carefully. Because of the digital format, pre-service teachers could arrange, modify and/or work with these materials according to their evolving understandings. In addition, as stated above, they would often share materials digitally with their learning networks, especially through Facebook, when they had Wi-Fi access.

Moreover, the pre-service teachers consolidated understanding by drawing on virtual resources in the context of the real-world classroom, as in Donna's example of looking up online resources on guided reading to supplement what her lecturer was saying. They learned, too, how moving between real and virtual spaces could benefit their own pedagogical strategies as teachers, as well as their students' learning. Nancy noted, for instance, that her iPad had helped her develop an early learning centre display: 
"We used the iPad to show a YouTube video of ... sand art. So that was actually a part of the learning centre, to inspire the kids and give them some ideas" (Nancy, second interview, 3/11/11).

\section{Perceived limitations of iPads as learning tools}

Three common themes were identified from the cross-case analysis regarding the pre-service teachers' perceptions of the limitations of iPads as learning tools: device limitations, time limitations, and attitudinal limitations. All impacted the use of the iPads.

\section{Device limitations}

All eight participants indicated that in some ways, some of the time, iPads did not suit their preferences for generating documents. On the one hand, some participants, like Rose, preferred analogue composition, i.e., using a pen and paper:

I do like pen and paper. So when I start writing an assignment it is usually pen and paper. So when I am starting something or when I [am] doing my lesson plans I prefer to print out the proforma and writ[e] on it. (Rose, first interview, 15/8/11)

More commonly, participants expressed a preference for the greater flexibility of older devices like desktop computers or laptops. Jessica explained: "I didn't really see [the iPad] as something to use for study; just because I prefer something with a keyboard ... something with a big screen" (Jessica, first interview, 15/8/11). The lack of a keyboard and the relatively small screen size are limitations of many mobile devices, as noted in the literature (e.g., Chinnery, 2006; Cochrane, 2007) and, while iPad screens are certainly larger than those of mobile phones, this may still be significant when it comes to composing long texts or creating multimedia artefacts.

Among more technologically experienced users, the focus was less on the limitations of the hardware than the limitations of the software. Nancy, who self-assessed her prior ICT experience as "high", explained: "While this is a fantastic tool ... one of the limitations is that ... it doesn't have Flash and it also doesn't have a lot of the programs that a PC has or even a Mac does" (Nancy, first interview, 11/8/11). Echoing Nancy's concerns, David, who had rather modestly assessed his prior ICT experience as "medium", noted:

I did bring in my laptop and used that a couple of times because it had software that the iPad is unable to use ... the iPad is limited in the scope in how I want to use it and how I want to use the applications. (David, second interview, 17/10/11)

These comments are very much in line with concerns expressed in the literature about the possible disadvantages of an app-based approach to new technologies (e.g., McKenzie, 2012; Quitney Anderson \& Rainie, 2012), especially when it comes to creating rather than consuming materials.

Participants with all levels of prior experience noted the limitation of the Wi-Fi-only iPads they had been loaned, as opposed to more flexible 3G-enabled iPads which would have allowed them more regular access to their personal learning networks (in line with Puentedura's [2002] conception of mobile devices). As a result, some used their smartphones in preference to the iPads, but it was clear that many were juggling at least three devices - a smartphone, a computer (whether a laptop or desktop device), and an iPad - as seen in Nancy's comment:

I think [the iPad] would have been a lot more useful if it had had [3G] because then we could truly use it anywhere. As it is, to access the internet, which a lot of ... us do, a lot of the time, whether it is for email or Facebook, or checking for information on Google or Wikipedia or the library or whatever, and with this you can set up your phone as a mobile wireless and connect through that, and if you have your phone then you might as well use your phone. If you are home and you have the Wi-Fi, or at uni - the uni is good because you don't have your other computer there - that is when it is very useful. At home you have [a] computer to use. So I think it would have been a more useful tool out and about if it had the $3 \mathrm{G}$ card in it. (Nancy, first interview, 11/8/11) 
The fact that several participants, including David and Nancy, as indicated in their quotes here, used both a computer and an iPad suggests that some students are gravitating naturally to a position which is in line with recent research suggesting students may benefit from using both a tablet and a computer, but for different purposes in different contexts (Oakley et al., 2012; Pegrum et al., 2013).

For some, using other devices in preference to iPads was not only a matter of hardware, software or network access, but also familiarity. Jessica stated: "I know my way around [my computer] and when I am familiar and comfortable I tend to like to stay there" (Jessica, first interview, 15/8/11), while Nancy said: "I have my own computer set up at home that I use for most things and I have got set up exactly how I want it" (Nancy, first interview, 11/8/11). This was further supported by a comment from the focus group interview: "I was using a laptop so to have to switch to the iPad was actually really daunting for me ... it took me ages to get used to it and I probably didn't utilise it as much as I could have" (Focus group interview, 10/11/11).

Thus, the iPads were seen as having certain hardware limitations, compounded by software limitations, especially when it came to generating documents or artefacts. In this respect, they fell between the analogue possibilities at one end of the spectrum and the digital possibilities at the other, and in any case were a somewhat unfamiliar new option. It is possible that this might change with time, exposure, and additional modelling by lecturers or peers. But while iPads offer advantages when composing certain kinds of texts, such as taking multimedia notes in a classroom, it may be that more traditional digital devices currently offer greater benefits in some other contexts. The iPads' value for students could however be improved by investing in $3 \mathrm{G}$ rather than Wi-Fi-only iPads, which would allow more ubiquitous connection to personal learning networks and more seamless learning across formal and informal contexts.

\section{Time limitations}

Echoing the literature on teachers' engagement with new technologies (e.g., Pegrum et al., 2013), six preservice teachers mentioned time as an important factor when it came to exploring and using iPads. As Donna noted: "I feel that I need to be more engaged with the iPad ... I need time to discover things. I can't get it instantly" (Donna, second interview, 24/10/11). For Rose, a change in daily routine resulted in decreased use:

I am sure if I had more time I would use it more ... that could be a reason why I am not using it as much. Because I am using my car more, so I am not on the train and not using it as much. I was using it so much when I was using public transport (Rose, second interview, $17 / 10 / 11)$.

Another participant's use of the iPad decreased when he became a father during the trial: "I had a baby five weeks ago ... I have been using the iPad significantly less" (David, second interview, 17/10/11). Interestingly, however, one participant provided a contrasting perspective, explaining that an injury had dramatically increased her use of the iPad: "I fractured my right thumb. So it was strapped up and I couldn't use my hand at all ... I used the iPad a lot. I used the recording devices, took notes, and transcribed. It came in really handy" (Ruth, second interview, 24/10/11).

\section{Attitudinal limitations}

Two of the participants shared how their attitudes towards the technology restricted the ways they used the iPads. While acknowledging the place of ICTs in education, they described themselves as "technology challenged", as illustrated by Jessica's initial comments:

I was also very nervous because I am just hopeless at that sort of stuff. I just hate it. I am technology challenged, that would be a good way to describe me ... I didn't really see it as something to use for study. (Jessica, first interview, 15/8/11)

Her comments in the second interview reconfirmed this attitude: "I just don't see the inherent value in [the iPad]" (Jessica, second interview, 24/10/11). In this, she echoed the views of the lecturer mentioned 
earlier who chose not to use her iPad in her teaching. While, again, some more time and more lecturer and peer modelling of the benefits of these devices might shift such attitudes to some degree, it may also be that - in light of many educators' concerns about the current lack of evidence of the educational value of these devices (e.g., Mather, 2012; Walters \& Baum, 2011) - there is room for a healthy degree of technoscepticism.

\section{Summary and recommendations}

Despite some clear limitations, the iPad 2 was generally experienced by the pre-service teachers as supporting their learning in multiple ways. These devices helped them develop their understanding of content by recording and recalling information, consolidating and extending knowledge, and reflecting on learning. The last of these themes, evident in the case of three of the eight participants, shows that they had begun to develop into reflective practitioners and learners. Given the positive impact of lecturers' modelling of pedagogically appropriate uses of iPads, it would be beneficial for lecturers to focus on explicitly encouraging students to exploit the capacity of these devices to support a higher level of reflection. Of course, this would require the lecturers themselves to be convinced of the value of the devices and to have a solid grasp of their pedagogical possibilities. The devices also helped pre-service teachers develop their understanding of pedagogy by reflecting on key themes such as student engagement, group work, and materials, but again, further reflection on best practice could be explicitly encouraged by lecturers who are well-disposed towards the use of the devices and well-versed in their educational possibilities.

In addition, the iPads permitted students to stay connected with their PLNs, consisting of resources and other people, mainly peers, and to stay organised by storing and accessing materials in a virtual space reachable from multiple real world spaces. In this way, the iPads supported students' seamless learning across formal and informal contexts and helped them access their support networks wherever they were, subject to the availability of a Wi-Fi connection. Nevertheless, the inherent limitations of the devices - in terms of hardware, software and network access - caused some obstacles, as did students' time and attitudinal limitations. The latter can at least be partially addressed by lecturers through classroom strategies, while the availability of $3 \mathrm{G} / 4 \mathrm{G}$-enabled devices, as opposed to Wi-Fi-only devices, could significantly augment their integration into students' everyday lives.

In conclusion, our research has generated the following recommendations on how best to use iPads to support the learning not only of pre-service teachers, but of higher education students in general:

a) Provide explicit technological and, more importantly, pedagogical input for lecturers on how to use iPads, especially to encourage a higher level of student reflection.

b) Ensure that lecturers provide explicit input on, and model best practice with, iPads, so that students learn how to use them in a pedagogically appropriate manner, including engaging in a higher level of reflection.

c) Encourage students to use iPads to complement existing digital devices, using each for the most appropriate purposes in the most appropriate contexts.

d) Encourage students to use their multiple devices, ideally including 3G/4G-enabled iPads, to learn seamlessly across formal and informal contexts, accessing the support of their personal learning networks as they do so.

In coming years we will see the further development of iPads, other kinds of tablets, and indeed other kinds of mobile technologies. In the meantime, the recommendations above are designed to help foster best practice in using the current generation of iPads to improve students' learning and, in particular, to help them develop the reflective skills needed not only by pre-service teachers but all 21 st century learners.

\section{Acknowledgements}

We would like to thank The University of Western Australia for funding this project through a Teaching Fellowship entitled Student Experiences of iPads as a Tool for Tertiary Learning, awarded to Associate Professors Christine Howitt and Mark Pegrum in 2011-2012. We would like to express particular thanks 
to the Dean of the Graduate School of Education, Winthrop Professor Helen Wildy, who funded the purchase of iPads for loan to the Master of Teaching students.

\section{References}

Backer, E. (2010). Using smartphones and Facebook in a major assessment: The student experience. EJournal of Business Education \& Scholarship of Teaching, 4(1), 19-31. Retrieved from http://pandora.nla.gov.au/pan/84582/201106040131/www.ejbest.org/upload/eJBEST_Backer_2010_4 (1).pdf

Barack, L. (2010). Is the iPad fit for school? School Library Journal, 56(5), 12.

Chinnery, G. M. (2006). Going to the MALL: Mobile assisted language learning. Language Learning \& Technology, 10(1), 9-16. Retrieved from http://llt.msu.edu/vol10num1/pdf/emerging.pdf

Cochrane, T. (2007). Mobile web2 pedagogies. In D. Parsons \& H. Ryu (Eds.), Proceedings of the Conference on Mobile Learning Technologies and Applications (MoLTA) 2007, Massey University, Auckland, New Zealand (pp. 31-38). Retrieved from http://molta.massey.ac.nz/massey/fms//Molta/Cochrane.pdf

Cochrane, T., \& Bateman, R. (2010). Smartphones give you wings: Pedagogical affordances of mobile web 2.0. Australasian Journal of Educational Technology, 26(1), 1-14. Retrieved from http://www.ascilite.org.au/ajet/ajet26/cochrane.pdf

Cochrane, T., Narayan, V., \& Oldfield, J. (2011). iPadagogy: Appropriating the iPad within pedagogical contexts. Proceedings of the $10^{\text {th }}$ World Conference on Mobile and Contextual Learning, 18-21 October 2011, Beijing, China: mLearn2011 (pp. 146-154). Beijing: Beijing Normal University. Retrieved from http://mlearn.bnu.edu.cn/source/Conference_Procedings.pdf

Cohen, L., Manion, L., \& Morrison, K. (2000). Research methods in education (5th ed.). London: Routledge-Falmer.

Cristol, D. \& Gimbert, B. (2011). Accessing mathematics through mobile learning devices for students with learning difficulties. Proceedings of the 10th World Conference on Mobile and Contextual Learning, 18-21 October 2011, Beijing, China: mLearn2011 (pp. 321-327). Beijing: Beijing Normal University. Retrieved from http://mlearn.bnu.edu.cn/source/Conference_Procedings.pdf

DEECD [Department of Education and Early Childhood Development] [Victoria, Australia]. (n.d.). iPad trial. iPads for learning. Retrieved from http://www.ipadsforeducation.vic.edu.au/ipad-student-trial

Ernst, H., \& Harrison, J. (2011). The use of mobile learning to develop understanding of biomedical sciences. Proceedings of the 10th World Conference on Mobile and Contextual Learning, 18-21 October 2011, Beijing, China: mLearn2011 (pp. 66-69). Beijing: Beijing Normal University. Retrieved from http://mlearn.bnu.edu.cn/source/Conference_Procedings.pdf

Ferriter, W. M., Ramsden, J. T., \& Sheninger, E. C. (2011). Communicating and connecting with social media. Bloomington, IN: Solution Tree Press/NAESP.

Franklin, T., \& Peng, L. W. (2008). Mobile math: Math educators and students engage in mobile learning. Journal of Computing in Higher Education, 20(2), 69-80.

Franklin, T., Sexton, C., Lu, Y., \& Ma, H. (2007). PDAs in teacher education: A case study examining mobile technology integration. Journal of Technology and Teacher Education, 15(1), 39-57.

GSMA [Groupe Spécial Mobile Association]. (2011a). Mobile education in the United States. London: GSMA. Retrieved from http://www.gsma.com/connectedliving/wpcontent/uploads/2012/03/usa110811interactive1.pdf 
GSMA [Groupe Spécial Mobile Association]. (2011b). Mobile education landscape report. London: GSMA. Retrieved from http://www.gsma.com/connectedliving/wpcontent/uploads/2012/05/landscape110811interactive.pdf

Herrington, J., Herrington, T., Ferry, B., \& Olney, I. (2008). New technologies, new pedagogies: Using mobile technologies to develop new ways of teaching and learning. Final report to the Australian Learning and Teaching Council. Strawberry Hills, NSW: Australian Learning and Teaching Council. Retrieved from http://www.olt.gov.au/resource-new-technologies-new-pedagogies-uow-2009

Hu, W. (2011, January 4). Math that moves: Schools embrace the iPad. The New York Times. Retrieved from http://www.nytimes.com/2011/01/05/education/05tablets.html

Hwang, W.-Y., Chen, C.-Y., \& Chen, H. S. L. (2011). Facilitating EFL writing of elementary school students in familiar situated contexts with mobile devices. Proceedings of the 10th World Conference on Mobile and Contextual Learning, 18-21 October 2011, Beijing, China: mLearn2011 (pp. 15-23). Beijing: Beijing Normal University. Retrieved from http://mlearn.bnu.edu.cn/source/Conference_Procedings.pdf

ICT signs \$32m tablet PC contract. (2012, May 10). Bangkok Post. Retrieved from http://www.bangkokpost.com/news/local/292692/ict-signs-32m-tablet-contract

iPads for young students. (2012, February 1). The West Australian. Retrieved from http://au.news.yahoo.com/thewest/a/-/breaking/12778793/ipads-for-young-students/

iPads reinvent Adelaide science. (2011, Winter). Wheels for the Mind, pp. 6-7. Retrieved from http://auc.edu.au/media/wheels/Wheels_2011_Winter.pdf

Jennings, G., Anderson, T., Dorset, M., \& Mitchell, J. (2010). Report on the Step Forward iPad pilot project. Trinity College: University of Melbourne. Retrieved from https://docs.google.com/viewer?a=v\&pid=explorer\&chrome=true\&srcid=0B5lvGCuvwcgXZWZkYm EzNDMtNmQ1OS00NmRhLTlhYmItOTU5NmVhYWJINDA1\&hl=en\&pli=1

JISC. (2005). Innovative practice with e-learning: A good practice guide to embedding mobile and wireless technologies into everyday practice. Bristol: HEFCE. Retrieved from http://www.jisc.ac.uk/media/documents/publications/innovativepe.pdf

Johnson, L., Adams, S., \& Cummins, M. (2012). The NMC Horizon Report: 2012 Higher Education Edition. Austin, TX: The New Media Consortium. Retrieved from http://www.nmc.org/publications/horizon-report-2012-higher-ed-edition

Johnson, L., Adams, S., \& Haywood, K. (2011). The NMC Horizon Report: 2011 K-12 Edition. Austin, TX: The New Media Consortium. Retrieved from http://media.nmc.org/iTunesU/HR-K12/2011/2011Horizon-Report-K12.pdf

Jones, A., \& Issroff, K. (2007). Motivation and mobile devices: Exploring the role of appropriation and coping strategies. Research in Learning Technology, 15(3), 247-258.

Kolowich, S. (2010, December 22). Apple of their eye? Inside Higher Ed. Retrieved from http://www.insidehighered.com/news/2010/12/22/college_students_test_drive_the_apple_ipad

Kukulska-Hulme, A., Sharples, M., Milrad, M., Arnedillo-Sánchez, I., \& Vavoula, G. (2009). Innovation in mobile learning: A European perspective. International Journal of Mobile and Blended Learning, $1(1), 13-35$.

Looi, C.-K., Seow, P., Zhang, B., So, H.-J., Chen, W., \& Wong, L.-H. (2010). Leveraging mobile technology for sustainable seamless learning: A research agenda. British Journal of Educational Technology, 41(2), 154-169. 
Mather, J. (2012, February 8). Tablets are cool but are they smart. Australian Financial Review. Retrieved from http://afr.com/p/national/tablets_are_cool_but_are_they_smart_6yTxDkqrbjYqiXYviWSVDL

McCaffrey, M. (2011, February 8). Why mobile is a must. THE Journal. Retrieved from $\mathrm{http} / / /$ thejournal.com/articles/2011/02/08/why-mobile-is-a-must.aspx

McElvaney, J., \& Berge, Z. (2009). Weaving a personal web: Using online technologies to create customized, connected, and dynamic learning environments. Canadian Journal of Learning and Technology, 35(2). Retrieved from http://www.cjlt.ca/index.php/cjlt/article/viewArticle/524/257

McKenzie, H. (2012, April 27). Web 2.0 is over, all hail the age of mobile. Pando Daily. Retrieved from http://pandodaily.com/2012/04/27/web-2-0-is-over-all-hail-the-age-of-mobile/

Melhuish, K., \& Falloon, G. (2010). Looking to the future: M-learning with the iPad. Computers in New Zealand Schools: Learning, Teaching, Technology, 22(3). Retrieved from http://education2x.otago.ac.nz/cinzs/mod/resource/view.php?id=114

Merriam, S. B. (2009). Qualitative research: A guide to design and implementation. San Francisco: Jossey-Bass.

Murray, O. T., \& Olcese, N. R. (2011). Teaching and learning with iPads, ready or not? TechTrends, $55(6), 42-48$.

Naismith, L., Lonsdale, P., Vavoula, G., \& Sharples, M. (2006). Report 11: Literature review in mobile technologies and learning. Bristol: Futurelab. Retrieved from http://www2.futurelab.org.uk/resources/documents/lit_reviews/Mobile_Review.pdf

Oakley, G., Pegrum, M., Faulkner, R., \& Striepe, M. (2012). Exploring the pedagogical applications of mobile technologies for teaching literacy. Report for the Association of Independent Schools of Western Australia. Retrieved from http://www.education.uwa.edu.au/research/?a=2195652

Pachler, N., Bachmair, B., \& Cook, J. (2010). Mobile learning: Structures, agency, practices. New York: Springer.

Patten, B., Arnedillo-Sánchez, I., \& Tangney, B. (2006). Designing collaborative, constructivist and contextual applications for handheld devices. Computers \& Education, 46(3), 294-308.

Patton, M. Q. (2002). Qualitative research and evaluation methods (3rd ed.). Thousand Oaks, CA: Sage.

Pegrum, M. (2009). From blogs to bombs: The future of digital technologies in education. Crawley, WA: UWA Publishing.

Pegrum, M., Oakley, G., \& Faulkner, R. (2013). Schools going mobile: A study of the adoption of mobile handheld technologies in Western Australian independent schools. Australasian Journal of Educational Technology 29(1), 66-81. Retrieved from http://ascilite.org.au/ajet/submission/index.php/AJET/article/view/64/25

Puentedura, R. R. (2012, September 14). Building upon SAMR. Presentation at Presbyterian Ladies' College, Perth. Retrieved from http://www.hippasus.com/rrpweblog/archives/2012/09/03/BuildingUponSAMR.pdf

Quitney Anderson, J., \& Rainie, L. (2012, March 23). The web is dead? Washington, DC: Pew Internet \& American Life Project. Retrieved from http://pewinternet.org/ /media//Files/Reports/2012/PIP_Future_of_Apps_and_Web.pdf

Richardson, W., \& Mancabelli, R. (2011). Personal learning networks: Using the power of connections to transform education. Bloomington, IN: Solution Tree Press. 
Strauss, A., \& Corbin, J. (1990). Basics of qualitative research: Grounded theory procedures and techniques. Newbury Park, CA: Sage.

Walters, E. A., \& Baum, M. (2011). Point/counterpoint: Will the iPad revolutionize education? Learning \& Leading with Technology, 38(7), 6-7. Retrieved from http://www.learningandleadingdigital.com/learning_leading/201105\#pg8

Corresponding author: Mark Pegrum, mark.pegrum@uwa.edu.au

Australasian Journal of Educational Technology (C) 2013.

Please cite as: Pegrum, M., Howitt, C., \& Striepe, M. (2013). Learning to take the tablet: How preservice teachers use iPads to facilitate their learning. Australasian Journal of Educational Technology, 29(3), 464-479. 